\title{
An Analysis of Students' Mathematical Reasoning and Mental Computation Proficiencies
}

\author{
Parmjit Singh", Teoh Sian Hoon, Nurul Akmal Md Nasir, Cheong Tau Han, Nor Syazwani Md Rasid, \\ Joseph BZH
}

Faculty of Education, University Teknologi MARA Selangor, Malaysia

Received July 15, 2020; Revised August 22, 2020; Accepted September 17, 2020

\section{Cite This Paper in the following Citation Styles}

(a): [1] Parmjit Singh, Teoh Sian Hoon, Nurul Akmal Md Nasir, Cheong Tau Han, Nor Syazwani Md Rasid, Joseph BZH, "An Analysis of Students' Mathematical Reasoning and Mental Computation Proficiencies," Universal Journal of Educational Research, Vol. 8, No. 11, pp. 5628 - 5636, 2020. DOI: 10.13189/ujer.2020.081167.

(b): Parmjit Singh, Teoh Sian Hoon, Nurul Akmal Md Nasir, Cheong Tau Han, Nor Syazwani Md Rasid, Joseph BZH (2020). An Analysis of Students' Mathematical Reasoning and Mental Computation Proficiencies. Universal Journal of Educational Research, 8(11), 5628 - 5636. DOI: 10.13189/ujer.2020.081167.

Copyright $\bigcirc 2020$ by authors, all rights reserved. Authors agree that this article remains permanently open access under the terms of the Creative Commons Attribution License 4.0 International License

\begin{abstract}
Mathematical computation and reasoning are the core of mathematics teaching and learning. It is important for students to put on their thinking caps instead of merely memorizing facts and figures. This study was conducted to investigate mathematical reasoning and mental computation proficiencies among primary school students in Malaysia. This outcome would depict students' ability, whether the reasoning is logical or merely applying formulas without making sense of it. Utilizing a descriptive correlational design, a total of 213 primary school students comprising Primary 5 and Primary 6 participated in the study. The findings of the study show both Primary 5 and Primary 6 students have a moderately high level of mental computation proficiency with scores of 15.36 and 22.9 respectively (from a maximum score of $30)$. On the other hand, students obtained a low-level proficiency in the mathematical reasoning test with scores of $14.83(\mathrm{SD}=6.76)$ and $18.74(\mathrm{SD}=6.45)$ for primary 5 students and primary 6 students respectively from a maximum score of 70 . How well do current exams grades reflect the student's proficiency in mathematical reasoning? The outcome indicates that the school grades do not guarantee the ability to solve complex, mathematical problems, thus does not reflect their ability in mathematical reasoning and mental computational.
\end{abstract}

\footnotetext{
Keywords Mathematical Reasoning, Mental Computation, Teaching, Learning, Understanding, Proficiency
}

\section{Introduction}

Every student must be equipped with basic mathematics skills which will assist them in their daily lives. This is important to face the dynamics of the transforming world. In this 21 st century, coupled with the rapid technological changes, mathematical skills will enable students to be adaptable, flexible, resilient, malleable and creative. These skills not only make the students function well in society, but also be instrumental in strengthening productivity. The overgeneralisation of what mathematical skills entail is merely the ability to calculate. However, the overwhelming data around us drives us to sort and categorise by patterns, correlating, evaluating and interpreting the data. These are also part of mathematical skills that students need to make sense of especially among primary school students. The two more important domains in mathematical skills are mathematical reasoning and mental computation proficiency, both coincidentally being higher levels of cognitive skills. Both mathematical reasoning and mental computation proficiency need to be cultivated as these skills are utilised frequently in our daily lives.

This notion has been echoed by researchers in the field of Mathematics Education where classroom activities should go beyond calculation and getting right answers. Activities must be challenging cognitively like reasoning 
demands in solving mathematics problem. Several researchers relate reasoning to processes of explaining and generalizing [1-2] while some relate to proof and ways of proving $[3,4]$ and a few relate to manners of argumentation where specific argumentative strategies are emphasized [5]. Gurbuz \& Erdem[6] best defined it as the processes in solving complex problems that are not easy to be solved. There is a need to use the wh-questions, creative, logical and critical thinking styles to derive the answer. Often, mathematics is taught without stating the learning objectives and the usage in daily life. Most of the time, students are able to apply formulas, calculate and get the right answers. However, many of these students cannot reason it out and make sense of it. Studies e.g.[1,2,5] have depicted that the retention of mathematical skills is greater when it makes sense to the students and they are able to make sense of it, which equates mathematical reasoning.

There is a necessity in investigating students' reasoning proficiency because the information made available to teachers on their students' reasoning bridges the gap between teachers' teaching and students' learning. Fennema, Franke and Carpenter [7] reported that the data on learner's reasoning process was presented to the teachers. This useful information made teachers reflect on their own teaching. Teachers reorganised not only their lessons, but also the classroom, disclosing some comments, " $\ldots$ to expand her expectations of learners."; “... the more problems I asked the better they got" (p. 579). If the teacher is unaware of the learners' reasoning proficiency and abilities, the assignments or even exercises may not be suitable for them. The data given to the teachers made them realise where the learners had difficulties and helped to tackle that area. Such insight into students' reasoning processes can be utilised to plan more engaging lessons in Mathematics, thus developing a better curriculum.

The second cognitive domain for this paper refers to mental computation. Lately, an influx of new methods for mental computation such as KUMON, UCMAS and Math Monkey have been flooding the education community in their stance of a new way of learning mathematics where among others, rapid instant recall of number computation is propounded. Trafton [8] defined mental computation as a non-standard method of getting the answers precisely. Reys [9] added to this definition that this is done without the help of calculators or any gadgets. However, another perspective of mental computation is given in the parent resources page of the [10] website. The article claims that, "Mental computation refers to the process of working out and obtaining exact or approximate answers mentally." It adds on that the students gather various strategies and then select the ones that are more practical. The implication is that teachers have to expose students to various strategies. The inculcation of promoting this among students in school is of paramount significance for enhancing students learning of mathematics. Many parents have joined this wagon and testified that it has played a major role in their child's success in the primary school [11].

In a study done decades ago by Reys, et. al. [12] among Grade 2 to Grade 8 Japanese pupils, it was discovered that teaching using visual or oral presentation significantly yield better results. Although the strategies for mental computation were insufficient, the pupils were able to recall and use some of the observed strategies that were familiar to them. This finding concurs with [10] article, where students are able to choose a strategy that works well for them and in the process, they develop good mathematical reasoning and number sense. Leung [13] elucidated that these East Asian students have similar cultural aspects that are linked to mathematics teaching and learning: (1) Examination culture; (2) Belief in effort; (3) Memorization and practice. On the contrary, students spend too much time copying and making notes in a mathematics lesson than to comprehend what was taught and make sense of it [14]. It is undeniable that students are hard-working and put in lots of effort, but probably due to memorization and rote learning, inhibits their conceptual advances in mathematical knowledge.

Research decades ago has also shown that students strong in mental computation also display strong reasoning sense $[15,16]$. Similarly, the current trend also suggests that instruction in mental computation and estimation can support the development of reasoning in children $[17,18$, 6]. In fact, mental computation and estimation is expected at school level as it covers over $80 \%$ of problem-solving situations and it involves computing numbers accurately without the assistance of any gadgets or devices. In the mathematics curriculum, numbers and operations are the foundation of its learning and making sense of what numbers are, the significance, representation and relationship are key to the growth of reasoning proficiency. Mathematical thinking and unaided computation have vital roles in our school system that learners should have an array of experience utilizing these abilities.

\section{What about This Situation in Malaysia as the Focal of This Paper?}

Studies over the decades have shown in Malaysia that students have difficulties applying facts and formula in their daily lives despite having high scores in standardized tests [19-22]. This scenario of school mathematics deficiency is a common feature around the world and was confirmed by [23] that what is learned in school and common sense are becoming restricted. Basically, without much comprehension and justification of what is learnt, students become blind supporters of rules [24]. Steffee [25] said:

The current notion of school mathematics is based almost exclusively on formal mathematical procedures and concepts that, of their nature, are very remote from the conceptual world of the children who are to learn them. (p. 5) 
This elucidation was about three decades ago and is it still prevalent at current time?

In a study by [19], they elucidated that many students have a tendency to give answers to a question in tests or exercises without checking if the answers make any sense. They illustrated how students were following rules without reason. In one of the tasks given, if it takes 9 workers 5 hours to mow a certain lawn, how long would it take 6 workers to mow the same lawn? (Assuming that the workers are all performing at the same rate and all working for the entire time). In this task, $78.7 \%$ of the students obtained the answers as $31 / 3$ hours without a logical sense that it should be more than 5 hours! This was similarly echoed decades ago depicting students don't seem to be using reasoning process when they submit answers that are patently absurd or wrong [26].

In the Malaysian school climate, it seems that students' natural thinking "becomes gradually replaced by attempts at rote learning, with a disaster as a result" [27] and as such, there is a mismatch between the standardized examination results and the mathematical competency. For many students, mathematics taught in school is all about rote learning without much meaning attached to it. The straw that broke the camel's back was Malaysians student's performance in the TIMSS and PISA studies that triggered great interest among academics, politicians, and stakeholders. In PISA and TIMSS, numeracy, also known as mathematical literacy is measured through mathematical problems that require analysis, reasoning and effective communicative skills be it quantitatively, spatially, or any other mathematical concept [28]. The results indicated that students in Malaysia were falling behind in TIMSS because they lacked the opportunity to develop Higher Order Thinking Skills (HOTS) especially in the context of mathematical reasoning. The performance of Malaysian students was way behind compared to our neighbours especially Singapore, and Vietnam.

Due to Malaysia declining performance over the years, in 2011, a new KSSR curriculum (in 2011) for the primary level and KSSM curriculum (in 2016) for secondary were introduced. This new curriculum aimed to produce individuals who are mathematically "fikrah" which means individual who can think and reason mathematically, creative and innovative as well competent in the use of mathematical knowledge and ability effectively and responsibly to solve problem and make decisions. In this new curriculum, reasoning has been pointed out as one of the basic competences in the learning of school mathematics. It associates with the combination of reasoning and thinking in the teaching and learning of mathematics.

Mathematical reasoning is nurtured over a period of time. For optimal results, there must be some form of consistency in the learning and this must be done daily [29, p. 21]. The consistency is also dependent on the methodology used to present the topic and not on the variety of topics learnt [30]. These reasoning skills developed by students in early grades may accompany them throughout their school lives. Many studies such as [6] and [17] stress that schools must explicitly plan to improve mathematical reasoning in direct relation to mathematical concepts. This complex, multifaceted and dispositional synthesis is not found in any particular topic in the textbook. In fact, the development of reasoning, sophisticated thinking ability and number sense comes from an array of exercises that infuses mathematical knowledge [31] which was elucidated three decades ago. The question to ponder, since the implementation of the new KSSR curriculum for primary school, how much of it has enhanced students' learning of mathematics especially in the contexts of their reasoning proficiency?

Students who do well in mathematics do have an assortment of algorithms. Interestingly, have we tried to scrutinize the nature of the knowledge in terms of their reasoning and mental computation proficiency?Mathematical reasoning and mental computations are two fundamental domains of mathematics learning at all grade levels. The nucleus of this research lies in accelerating the progress of students in terms of learning mathematics. In light of this, it is of utmost importance that the level of their progress is measured numerically as far as their reasoning computation abilities is concerned. Teachers need to know what constitutes the students' learning of mathematics and this knowledge is very much correlated with students' mathematical reasoning and mental computation. It will provide teachers an effective means to assess learners' current levels of reasoning and computation in the area of whole numbers, fractions, decimals, percent, ratio, money and estimation. This will also provide teachers with a sense of direction insofar as the learning process and the acquisition and progression of basic maths skills is concerned.

The students were adequately well versed with the basic mathematical concepts having gone through the process of learning them, and through this study, their reasoning, computation proficiency, and number sense, i.e. understanding numbers, their representation and meaning is to be assessed. Through this, it will be known whether the students possess the abilities to reason, or are they merely engaging in rote, mechanical processes to attain solutions, without considering whether or not the final product makes sense. Thus, this research was undertaken with the objective:

(i) To examine students' proficiency in mental computation and mathematical reasoning.

(ii) To examine the relationship between mental computation and mathematical reasoning proficiency.

\section{Methodology}

This study utilized an approach completely quantitative, whereby a descriptive correlation design was used, with the 
aim to investigate primary school student's proficiency in mental computation, mathematical reasoning and its relationship. A total of 213 student's upper primary students comprising among Primary Five $(n=115)$ and Primary Six $(n=79)$ participated in the study. These respondents were randomly selected from 5 schools in the State of Selangor. The detail demography of the respondents is show in Table 1.

Table 1. Demographic of respondents by years and genders

\begin{tabular}{|c|c|c|c|}
\hline \multirow{2}{*}{ Level } & \multicolumn{2}{|c|}{ Gender } & \multirow{2}{*}{ Total } \\
\cline { 2 - 3 } & Male & Female & \\
\hline \multirow{2}{*}{ Primary 5} & 39 & 79 & 118 \\
& $18.31 \%$ & $37.09 \%$ & $55.40 \%$ \\
\hline \multirow{2}{*}{ Primary 6} & 40 & 55 & 95 \\
& $18.78 \%$ & $25.82 \%$ & $44.60 \%$ \\
\hline \multirow{2}{*}{ Total } & 79 & 134 & 213 \\
& $37.09 \%$ & $62.91 \%$ & $100.00 \%$ \\
\hline
\end{tabular}

\section{Instrumentation}

Two paper and pencil test tests were used for the data collection purposes. The Mathematical Reasoning Test (MRT) was adapted from [6] while the Mental Computation Test (MCT) was adopted from [15].

\section{Mathematical Reasoning Test (MRT)}

The MRT instrument consists of 14 questions and students need to give a reason for their answer in each of the given questions.

\section{Example from Mathematical Reasoning Test}

1. Pages of a 15-page children's story book are to be numbered starting from 1 . How many numerals will have been used after this process is finished? Explain.

2. There are 5 schools with 8 classes in each school. Each class has 30 students. If we equally divide these students into 16 schools in another city, how many students will be in each school? Explain.

3. Aminah is pregnant. Her first 5 children are boys. Which one the following is correct for the sixth child? Explain.

(A) The sixth will probably be a girl.

(B) The sixth will probably be a boy.

(C) The possibility of the sixth to be a girl or boy is equal.

4. In question 14, specify the pattern between the numbers given and give the answer you think can replace "?" Explain.

$1,1,2,3, ?, 8$

The scoring for the Mathematical Reasoning Test was adopted from [6] based on the following 5 scale rubric:

0 . Incorrect answer, wrong justification;

1. Correct answer, wrong justification;

2. Incorrect answer, partially correct justification;
3. Correct answer, partially correct justification;

4. Incorrect answer, correct justification;

5. Correct answer, correct justification

\section{Mathematical Computation Test (MCT)}

The mental computation test adopted from [14] consists of 30 questions comprising multiple choice items based on correct or incorrect response. Multiple choice response sheets were distributed to all students. The questions were then projected one by one on the screen. Each question was displayed for 30 seconds. Students did not have the chance to return to the earlier unanswered questions. No calculators, paper and pencil, or working were allowed as it was based strictly on mental computation.

\section{Findings of Study}

The first section provides a glimpse of the academic backgrounds of the students involved in the study. Table 2 shows the mathematics grade obtained by the respondents in their mid-term year examination. The data shows $44.5 \%$ $(n=95)$ of the students obtained an A grade in their mid-year examination, followed by $31.6 \%(n=67)$ and $23.9 \%(n=51)$ with $B$ and $C$ grades respectively. In other words, approximately three fourths of the respondents obtained a B grade or better depicting an above average respondents involved in the study.

Table 2. Mid-Year Math Examination grade

\begin{tabular}{|c|c|c|}
\hline Grade & Frequency & Percent (\%) \\
\hline A & 95 & 44.5 \\
\hline B & 67 & 31.6 \\
\hline C & 51 & 23.9 \\
\hline Total & 213 & 100.0 \\
\hline
\end{tabular}

Table 3 depicts the grade these respondents expect to get in their year-end examination in mathematics. The data shows $82.2 \%(n=175)$ of students expect to get an A grade for their final year examination followed by $15.0 \%(n=32)$ percent expectation of $B$ grade and $2.8 \%(n=6)$ with $C$ grade. The analyses show that more than three-fourths of the respondents has a high confidence level based on their high expectation of getting an A grade on their year-end mathematics examination.

Table 3. Expectation of Final year-end examination grade

\begin{tabular}{|c|c|c|}
\hline Grade & Frequency & Percent (\%) \\
\hline A & 175 & 82.2 \\
\hline B & 32 & 15.0 \\
\hline C & 6 & 2.8 \\
\hline Total & 213 & 100.0 \\
\hline
\end{tabular}

The next section depicts the results obtained from the study.

Research Question 1: 
a) What is the level of students' achievement in mental computation test?

b) Is there a significant difference in mental computation test scores between primary 5 students and primary 6 students?

The hypothesis to be tested is:

$\mathrm{H} 0$ : There is no significant difference in mental computation test between primary 5 students and primary 6 students

H1: There is a significant difference in mental computation test between primary 5 students and primary 6 students.

Table 4 shows the mean score obtained by the primary 5 and primary 6 students' in the mental computation tests. The mean score obtained by the primary 6 students is 22.29 $(\mathrm{SD}=5.41)$ as compared to their primary 5 counterparts score of $15.36(\mathrm{SD}=6.37)$. In other words, the Primary 6 students obtained a percentage score of $74.3 \%$ (22.29/30 $\mathrm{x} 100)$ as compared to $51.2 \%(15.36 / 30 \mathrm{x} 100)$ by the primary 5 students. One can surmise that Primary 6 students obtained a moderately high score in the MCT as compared to their primary five counterparts. To determine if there is a significant difference in these scores (mean scores), an independent sample t-test was conducted (refer Table 4)

Table 4. Descriptive statistics and test in students "performance in mental computation test between primary 5 and primary 6

\begin{tabular}{|c|c|c|c|c|c|c|}
\hline Level & $\mathrm{N}$ & Mean & $\mathrm{SD}$ & $\mathrm{t}$ & $\mathrm{df}$ & $\mathrm{Sig}$ \\
\hline Primary 5 & 118 & 15.36 & 6.37 & & & \\
\hline Primary 6 & 95 & 22.29 & 5.41 & -8.435 & 211 & 0.000 \\
\hline Overall & 213 & 18.46 & 6.88 & & & \\
\hline
\end{tabular}

Maximum Score: 30

The analyses depict a significant difference [ $\mathrm{t}(211)=$ -8.435, p <0.05)] in mental computation test scores between primary 5 students and primary 6 students at the 0.05 level. Hence, the null hypothesis is rejected. This indicates that primary 6 students obtained a higher mean score than the primary 5 students in the MCT.

Research Question 2:

a) What is the level of student's achievement in mathematical reasoning test?

b) Is there a significant difference in mathematical reasoning test scores between primary 5 students and primary 6 students?

The hypothesis to be tested is:

$\mathrm{H} 0$ : There is no significant difference in mathematical reasoning test scores between primary 5 students and primary 6 students.

$\mathrm{H} 1$ : There is a significant difference in mathematical reasoning test scores between primary 5 students and primary 6 students.

Table 5 shows the test scores by primary 5 students and primary 6 students' in the mathematical reasoning test.

Table 5. Descriptive statistics and t test in students 'performance in mathematical reasoning test between primary 5 and primary 6

\begin{tabular}{|c|c|c|c|c|c|c|}
\hline Level & $\mathrm{N}$ & Mean & $\mathrm{SD}$ & $\mathrm{t}$ & $\mathrm{df}$ & $\mathrm{Sig}$ \\
\hline Primary 5 & 118 & 14.83 & 6.76 & & & \\
\hline Primary 6 & 95 & 18.74 & 6.45 & -4.278 & 211 & 0.000 \\
\hline Overall & 213 & 16.57 & 6.89 & & & \\
\hline
\end{tabular}

Maximum Score: 70

The mean scores for primary 5 students and primary 6 students are $14.83(\mathrm{SD}=6.76)$ and $18.74(\mathrm{SD}=6.45)$ respectively. The percentage score obtained by Primary 5 students and primary 6 students are a low $21.2 \%$ $(14.83 / 70 \times 100)$ and $26.8 \%(18.74 / 70 \times 100)$ respectively.

To investigate if there is a significant difference in the mathematical reasoning test scores, an independent sample t-test was conducted (refer table 6). The analyses reveal that there are significant differences $[\mathrm{t}(211)=$ $-4.278, \mathrm{p}<0.05)]$ in mathematical reasoning test scores between primary 5 students and primary 6 students at the 0.05 level. Hence, we reject the null hypothesis. Similarly, as in the mental computation test, the primary 6 students obtained a higher mean score in the Mathematical Reasoning test as compared to the primary 5 students.

Research Question 3:

Is there a significant relationship between mental computation test scores and mathematical reasoning test scores?

The hypothesis to be tested is:

H0: There is no significant relationship between mental computation test scores and mathematical reasoning test scores

H0: There is a significant relationship between mental computation test scores and mathematical reasoning test scores.

Table 6. Pearson Correlation between mental computation test scores and mathematical reasoning test scores

\begin{tabular}{|c|c|c|c|}
\hline \multicolumn{2}{|c|}{} & MCT & MRT \\
\hline \multirow{3}{*}{$\begin{array}{c}\text { MCT } \\
\text { and MRT }\end{array}$} & Pearson Correlation & 1 & $0.569^{* *}$ \\
\cline { 2 - 4 } & Sig. (2-tailed) & & 0.000 \\
\cline { 2 - 4 } & $\mathrm{N}$ & 213 & 213 \\
\hline
\end{tabular}

Table 6 shows that there is a moderately high and significant relationship $(r=0.569, \mathrm{p}<.05)$ between mental computation test scores and mathematical reasoning test scores at the 0.05 level. In other words, $32.4 \%$ ( $\mathrm{r} 2=0.324)$ of the mathematical reasoning scores can be explained by the scores obtained in the mental computation scores and vice versa.

\section{Discussion}

The findings indicate that the students involved in the 
study obtained a moderately high mental computation test scores where the primary 6 students $(\mathrm{M}=22.29)$ obtained a significant higher score than their primary 5 counterparts. This shows that teaching of mathematics in classroom are emphasizing mental computation especially on the development of students' ability to perform mental calculation for additions, subtractions, multiplications and divisions as part of their school curriculum. This finding was in tandem with the results obtained from [12] where Japanese students tend to excel in mental computations. This is because at an early age, these students are taught using abacus and a time table called jingle kuku where they are given a time frame to recite it speedily, both in the classroom and back home. They also elucidated that many of Japanese children also attend after-school math programs to enhance their mental computation prowess as they believe it as a predictor for mathematics achievement. Many parents in Malaysia have joined this wagon as well such as having their children enlisted in KUMON, UCMAS and Math Monkey programs and testified that it has played a major role in their child's success in the primary school [11]. This conception is in tandem with the Malaysian Standard-based Curriculum for Primary School (KSSR), indicating that the number concept must be focused in order to achieve high standards in the basic mathematical skills [32]. Although the students obtained a moderately high score, it was more towards rote learning than active learning as opposed to Japanese way of learning The Japanese way of learning of the abacus begins through the use of the physical equipment for arithmetical calculations. Here on, they move on to inculcate this in their thought process, through mental abacus, whereby they are to visualize the movement of beads in their minds and calculate accordingly. This active mental process is an exercise of MIND and HAND simultaneously. According to Li, et. al., [33], when the active hands and brain work together, it doubly improves the brain's functions that inadvertently enhances their mental computation prowess. The context of rote learning was exacerbated in previous study by [33], where they found that the students involved could recite the multiplication table learnt in schools but faced difficulty beyond it. (R denotes researcher and $\mathrm{S}$ denotes student)

$\mathrm{R}$ : What is seven multiply by four?

$\mathrm{S}$ : Twenty-eight (instant response)

R: Twelve multiply with five?

S: Sixty (instant response)

R: Seven multiply by six $(7 \times 6)$ ?

S: Forty-two (instant response)

R: Fourteen multiply with six $(14 \times 6)$ ?

Paused for a while and said

S: We have not learnt it in school.

R: What do you mean?

S: We learn our multiplication table till twelve only.

Here, $\mathrm{S}$ was not able to cognize that $14 \times 6$ is twice the quantity of $7 \times 6$

Previous studies [20,33, 21] have shown that Malaysian students' learning styles tend to excel in memorization of arithmetic facts emphasis on the development of children's ability to perform mental calculation for additions, subtractions, multiplications and divisions. However, their ability to reason mathematically was lacking due to rote memorization. This finding was also corroborated by [34] when she elucidated that some of East Asian ways of learning are labelled negatively, memorizing, and static learning style. The difference in findings between this study and Japanese education depicts the notion of active learning where it is literally about engaging and immersing students in an educational experience that enhances their performance. This notion was visible in the next variable of study in investigating students mathematical reasoning prowess.

In the mathematical reasoning test, the respondents obtained an overall low mean score of $16.57(\mathrm{SD}=6.89)$ with Primary 5 and Primary 6 test scores of 14.83 and 18.74 respectively out of a maximum score of 70 . In other words, the overall percentage score obtained by these students was $23.7 \%(16.57 / 70 \times 100)$. This indicates that students in this study have a low level of mathematical reasoning abilities and this is most likely due to the emphasis on memorization in classroom teaching and learning. Enhancing students' reasoning capabilities involves far more than accurate computation and rote memorization [35]. Understanding concepts is more important than getting the accurate answer. This finding was also corroborated with previous study by [27] where they revealed that children could follow the steps involved to solve questions on fraction, but had no idea of why the steps occurred in that manner. They suggested to change the methodology to focus more on active experiential learning of the concepts rather than merely on rules and algorithmic procedures. Mathematical reasoning could be developed by getting students to be actively involved in their mathematical thinking and representation of topics in distinct ways, rather than in terms of processes alone. According to Mack [36], in order to support and improve students' ability to make reasoning in mathematical complex relations, the improvement of relational reasoning needs to start from childhood and adolescence.

The results also depict a significant positive and moderately strong relationship $(\mathrm{r}=0.569)$ between mental computation and mathematical reasoning which was in tandem with previous studies [6]. This signifies that high attainment in mental computation corresponds directly with mathematical reasoning and vice versa. This was consistent with [37] study in investigating students' development of relational thinking, they similarly elucidated that there should be equal balance in teaching a skill and a concept in mathematics learning. They further elucidated that" even though [algebra] is first taught in secondary school years, importance should be given to the development of skills and concepts that will facilitate 
transition to algebra via student experiences and in-class discussions in early stages" (p. 131). It is enunciated that the rigid memorization of processes in the practice of arithmetic's takes away the opportunities for deep thought processes in developing the ability to reason and understand in maths.

Learning that takes place via memorisation without experiencing the activity tends to deteriorate in a short period of time. Edward Bolles, a specialist in memory, mentioned that, "We remember what we understand; we understand only what we pay attention to; we pay attention to what we want." [38, p. 9]. This quotation clearly spells out that what we remember is rather selective. Thus, understanding information in total at all cognitive levels is important in learning. Indirectly, memorization may not be the best way to learn.

\section{Conclusion and Recommendation}

This study found that the samples involved were above average students, based on their mid-year examination and expected grades. However, their performance in mathematical reasoning was poor. There is a widespread agreement that activities that promote experiential learning should be the focus when teaching mathematics. Teachers should transition from rote learning and computation to one that is based on understanding, reasoning and conceptualizing, simply because the goal would be to move beyond the mere rigid teaching of rules and quick processes without making sense of them. Doing this requires teachers to obtain information about students' thinking activities, their efforts at understanding, and their conceptual difficulties.

In helping students learn mathematics and develop their reasoning proficiency, teachers must identify the methods the student uses. Teachers must be more open-minded as they should realize that there are multiple ways of getting the answer. So, teachers should make conscious efforts to assist students to link what is being taught and what they already know so that learning becomes more meaningful. Previous studies have suggested methodologies for educators to link learning with prior knowledge for students reasoning development. The usage of pattern identification as fundamentals in solving math problems was recently suggested for this purpose [39]. The integration of patterns identification, usually involving numerical, spatial or logical relationships, provides opportunity for informal sharing ideas and justification on these recognitions among learners can promote the development of representation and abstraction of math structures that inadvertently enhances their reasoning prowess. This idea was also suggested a decade ago [40] depicting the need for intervention program in promoting abstraction of patterning in math learning. They elucidated the need to cater for learners' affection of math learning, skills development and engage them in challenging mathematical reasoning learning experiences.

This study utilized a purely quantitative approach in analyzing students' mathematical reasoning and mental computation proficiencies. Future research and investigation should focus on students' thought processes using a qualitative approach via interviews. The qualitative interpretive via interviews will enable to relate with students' interpretation and construction of knowledge based on prior learning such as how they construct their reasoning and what meaning they attribute to their experience in relations to mathematical knowledge. Another possible direction for future research is investigating the use of metaphors as precursor for mathematical reasoning development. These metaphors are tools that provide scaffolding in structuring the thought process of learners. Conceptualizing and identifying the innate nature of learners' metaphors might provide some empirical findings of the thought processes of learners mental images and its relationship with their reasoning.

Making sense of what is learnt is part of mathematical thinking and ability to connect the mathematical operations learnt will enhance the quality of mathematical reasoning. Ultimately, learners must construct their own ways and means of operating to develop their mathematical reasoning. Mathematics educators can play an important role through pedagogical means. Educators must realize that beyond accuracy is the mathematical concept that needs to be strengthened. Understanding concepts and reasoning ability given in a series of activities that promote thinking would be the way forward in the 21 st century mathematics education.

The depth of mathematics knowledge is very important. This is how the quality of the knowledge is measured. The concern is always on the product; the precision of answers and not on the process; the way to arrive at the answer. The focus on the process will definitely empower the students' mathematical reasoning. This empowerment will allow students to utilize their prior knowledge wired across disciplines, unveiling the essence of mathematics. This is totally opposite of learning to get the right answer. Students tend to resort to the fastest way, i.e. memorizing, which does not really help in the growth of their reasoning and understanding. [43] Wittrock emphasized that learning with reasoning understanding is a generative process, and [44] asserted that to reason and understand is to be able to invent. The more students move away from the role of memorization and mechanical application of isolated procedures, and the more students move towards rich linkages, flexible generalization, active learning and productive beliefs, the more we can say that some degree of mathematical reasoning and understanding is present.

\section{Acknowledgments}

The authors would like to thank Universiti Teknologi MARA, Selangor and Ministry of Higher Education 
Malaysia for funding this project under the Fundamental Research Grant Scheme [600-IRMI/FRGS 5/3 (211/2019)].

\section{REFERENCES}

[1] Bishop, J., Lamb, L., Philipp, R., Withacre, I., Schappelle, B., \& Lewis, M. (2014). Obstacles and Affordances for Integer Reasoning: An Analysis of Children's Thinking and the History of Mathematics. Journal for Research in Mathematics Education, 45(1), 19-61.

[2] Makar, K. (2014). Young children's explorations of average through informal inferential reasoning. Educational Studies in Mathematics, 86(1), 61-78.

[3] Durand-Guerrier V. (2015) Reasoning, Proof and Proving in Mathematics Education. In: Cho S. (eds) The Proceedings of the 12th International Congress on Mathematical Education. Springer, Cham

[4] Stylianides, G. J. (2009). Reasoning-and-proving in school mathematcs textbooks. Mathematical Thinking and Learning, 11(4), 258-288

[5] Simon, C., Judith, F., Eva, van der B. \& Adam, E. (2018). Improving analytical reasoning and argument understanding: a quasi-experimental field study of argument visualization. Nature, Science of Learning, 3(1), 21.

[6] Gurbuz, R. \& Erdem. E. (2016). Relationship between mental computation and mathematical reasoning, Cogent Education, 3, 1, 1-18.

[7] Fennema, E., Franke, M. L., Carpenter, T, P \& Carey, D.A. (1993). Using Children's Mathematical Knowledge in Instruction. American Educational Research Journal, 30, 3, $555-583$.

[8] Trafton, P. R. (1986). Teaching computation estimation: establishing an estimation mind set. Retrieved on May 26, 2020 from http://ponce.inter.edu/cai/tesis/lmrivera/cap2.ht $\mathrm{m}$.

[9] Reys, B. J. (1986). Mental computation. Arithmetic Teacher, 32(6), 43-46.

[10] Deebing Heights State School (n.d.). Mental Computation Strategies. Retrieved on May 26, 2020 from https://deebingheightsss.eq.edu.au/Supportandresources/For msanddocuments/Documents/Parent\%20resources/mental-c omputation-strategies.pdf

[11] The Star Online (10 May 2019). Over 700 students recognised for exceptional. Retrieved on Jun 24, 2020 from https://www.thestar.com.my/metro/metro-news/2019/05/10/ over-700-students-recognised-for-exceptional-performance

[12] Reys, R. E., Reys, B. J., Nohda, N., \& Emori, H. (1995). Mental computation performance and strategies used by Japanese students. Journal for Research in Mathematics Education, 26, 304-326.

[13] Leung F.K. (2017) Making Sense of Mathematics Achievement in East Asia: Does Culture Really Matter?. In: Kaiser G. (eds) Proceedings of the 13th International
Congress on Mathematical Education. ICME-13 Monographs. Springer, Cham

[14] Yimin, W. (2013). The Constructive Learning Theory and English Situated-teaching [J]. Foreign Language Education, 2,021 .

[15] McIntosh, A. (1996). Mental computation and number sense of Western Australian students. In J. Mulligan \& M. Mitchelmore (Eds.), Children's Number Learning (pp.259-276). Adelaide: Australian Association of Mathematics Teachers.

[16] McIntosh, A., Reys, B., \& Reys, R. (1992). A propose frame work for examining basic number sense. For the Learning of Mathematics, 12, 2-8.

[17] Rolad, P., Kathy, M. \& Tess, M. (2019). The Impact of Mental Computation on Children's Mathematical Communication, Problem Solving, Reasoning, and Algebraic Thinking. Retrieved on June12, 2020 from https://www.athensjournals.gr/education/2018-2635-AJE-P ourdavood-02.pdf

[18] Kindrat, A.N., \& Osana, H.P (2018). The relationship between mental computation and relational thinking in the seventh grade. Fields Mathematics Educational Journal, 3, 6. Retrieved on January 12, 2020 from https://link.springer.com/article/10.1186\%2Fs40928-018-00 11-4\#citeas

[19] Parmjit, S., Teoh, S. H., Cheong, T. H., Md Rasid, N. S., Kor, L. K., \& Md Nasir, N. A. (2018). The Use of Problem-Solving Heuristics Approach in Enhancing STEM Students Development of Mathematical Thinking. International Electronic Journal of Mathematics Education, 13(3), 289-303.

[20] Aida Suraya (2015). Developing students' mathematical thinking: How far have we come? Retrieved on June 24, 2020 from http://www.educ.upm.edu.my/dokumen/FKKDI 1_BULETINEDUC.pdf.

[21] Radzi N. M., Abu, M. S., \& Mohamad, S. (2009). Math-oriented critical thinking skills in engineering. IEEE 2009 (Dec, 7 - 8) International Conference on Engineering Education (ICEED), 212-218. Retrieved on May 18, 2020 fromhttps://vdocuments.site/documents/ieee-2009-internati onal-conference-on-engineering-education-iceed-kuala-58c 2990a9663a.html

[22] Parmit, S. (2009). Variation in first year college students' understanding on their conceptions of and approaches to solving mathematical problems. Asian Journal for University Learning and Teaching, 5(1), 95-118.

[23] Resnick, L. B. (1987). Learning in school and out. Educational Researcher, 16(6), 13-20.

[24] Hiebert, J. (1984). Children's mathematics learning: The struggle to link form and understanding. Elementary School Journal, 84, 496-513.

[25] Steffe, L. P. (1994). Children's multiplying scheme. In G. Harel \& J. Confrey (Eds.), The development of multiplicative reasoning in the learning of mathematics (pp. 3-39). State University of New York Press.

[26] Menon, R. (2004). Preservice teachers' number sense. Focus on Learning Problems in Mathematics, 26(2), 49-61. 
[27] Parmjit, Singh, Narjidiah Abdul, Rahman, Mohd Adlan, Ramly and Teoh Sian, Hoon (2019). From Nonsense to Number Sense: Enumeration of Numbers in Math Classroom Learning. The European Journal of Social \& Behavioural Sciences EJSBS, 4, 2933 - 2947.

[28] OECD (2012). PISA 2012 Technical Report. Retrieved on June 12, 2020 fromhttps://www.oecd.org/pisa/pisaproducts/ PISA-2012-technical-report-final.pdf

[29] Thornton, C. A. \& Tucker, S.C. (1989). Lesson planning: the key to developing number sense. The Arithmetic Teacher, 36 (6), 18-21.

[30] Van De Walle, J. \& Watkins, K. B. (1993). Early development of number sense. In Jansen, R.J. (Ed.) Research ideas for the classroom (pp. 127-150). New York, New York: Macmillan Publishing Co.

[31] Greeno, J.G. 1991. Number sense as situated knowing in a conceptual domain. Journal for Research in Mathematics Education, 22, 170-218.

[32] Malaysia Education Blueprint (2013 - 2025). Retrieved on May 16, 2020 fromhttps://www.moe.gov.my/menumedia/m edia-cetak/penerbitan/dasar/1207-malaysia-education-bluep rint-2013-2025/file.

[33] Parmit Singh, Arba Abdul Rahman, Teoh Sian Hoon (2010). The newman procedure for analyzing primary four pupils errors on written mathematical tasks: A Malaysian perspective. Procedia-Social and Behavioral Sciences, 8, 264-271, Elsevier

[34] Helena Hing Wa Sit (2013). Characteristics of Chinese Students' Learning Styles. Retrieved on May 18, 2020 from
http://www.ipedr.com/vol62/008-ICLMC2013-M10004.pdf

[35] Mack, N. K. (1990). Learning fraction with understanding: Building on informal knowledge. Journal for Research in Mathematics Education, 21(1), 16-32.

[36] Singley, M and Bunge, S. A. (2014), Neurodevelopment of relational reasoning: Implications for mathematical pedagogy. Trends in Neuroscience and Education, 3, 3-37. Retrieved on May 24, 2020 fromhttps://escholarship.org/co ntent/qt6rz9j3xg/qt6rz9j3xg.pdf

[37] Kiziltoprak, A. and Kose, N. Y. (2017). Relational thinking: The bridge between arithmetic and algebra. International Electronic Journal of Elementary Education, 10, 1, 131-145.

[38] Keeley, M. (2011). Memory and the Importance of Review. Retrieved on May 25, 2020 fromhttp://faculty.bucks.edu/sp ecpop/memory.htm

[39] Ngo Truc Phuong and Nguyen Phu Loc (2020). Using the "Identifying a Pattern" Strategy to Solve Mathematical Word Problems of Proportional Quantities at Grade 5 Vietnam. Universal Journal of Educational Research 8(1), 105-111, 2020.

[40] Papic, M. M., Mulligan, J. T and Mitchelmore, M. C. (2011). Assessing the Development of Preschoolers' Mathematical Patterning. Journal for Research in Mathematics Education, 42(3), 237-269.

[41] Wittrock, M. C. (1974). Learning as a generative process. Educational Psychologist, 11(2), 87-95[44]

[42] Piaget J. (1973). To understand is to invent: The future of education. Penguin Books. Retrieved on July 3, 2020 from https: //unesdoc.unesco.org/ark:/48223/pf0000006133. 